\title{
The influence of growth regulators on the productive capacity of spring wheat
}

\author{
Vitaliy Isaychev, Nikolay Andreev*, and Myariam Bogapova \\ Ulyanovsk State Agrarian University, 432017 Ulyanovsk, Russia
}

\begin{abstract}
The author(s) studied the influence of various growth regulators on the yield and grain quality of the spring wheat variety "Zemlyachka" under the conditions of the forest-steppe of the Volga region. The studies have shown that pre-sowing treatment of seeds with growth regulators has a positive effect on the yield of the experimental crop, providing an increase of $0.17-0.40 \mathrm{t} / \mathrm{ha}$. The use of growth regulators in the technology of cultivation of spring wheat has a positive effect on the formation of grain quality indicators, which determine the technological and baking properties of products, such as the content of protein and starch, the quantity and quality of gluten, and the volumetric weight of grain.
\end{abstract}

\section{Introduction}

The regulation of plant growth and development with the help of physiologically active substances allows one to influence the individual stages of ontogenesis in order to mobilize the genetic potential of the plant organism and, ultimately, to increase the productive capacity and quality of crops.

In recent years, much attention has been paid to the development and application of growth regulators of a new generation with a wide range of physiological activity that are safe for humans and the environment. At the same time, growth regulators are considered an environmentally friendly and cost-effective way to increase the productive capacity of grain crops, allowing them to more fully realize the potential capabilities of plants.

Thus, the study of the influence of growth regulators of the new generation on the yield and quality of grain of spring wheat taking account of the specific soil and climatic conditions is important [1-4].

In connection with the previously mentioned, the purpose of our research was to study the effect of growth regulators on the productive capacity of spring wheat of the variety "Zemlyachka" under the conditions of the forest-steppe of the Volga region.

\section{Conditions and research methods}

The studies were conducted under laboratory and field conditions of Ulyanovsk State Agrarian University named after P.A. Stolypin. The experimental crop is the spring wheat variety "Zemlyachka", the method of carrying out the field experiment is the one generally accepted for small-plot fields, replication is four times, the layout of the variants in the experiment is randomized, the area of plots is $20 \mathrm{~m}^{2}$. Before sowing, the seeds were treated with growth regulators Crezacin, Energia, Albit, Gumi, Zircon, Extrasol, in concentrations recommended by the manufacturers. Heavy metals $(\mathrm{Hg}, \mathrm{Pb}, \mathrm{Cu}, \mathrm{Zn}, \mathrm{Cd}, \mathrm{Ni})$ in the grain were determined by plasma and electrothermal variants of atomic absorption spectroscopy with preliminary preparation of samples by the method of "dry" mineralization in the agrochemical laboratory of Ulyanovsk (State Standard 8.505.-84; MI -858.-85).

The soil of the experimental field is leached chernozem of medium thickness, medium loamy with the following agrochemical characteristics: humus content $-4.3 \%$ (medium humus soil), Rn - 5.8-6.8 (slightly acid), the content of mobile phosphorus and potassium respectively $107-142$ and $103-135 \mathrm{mg} / \mathrm{kg}$ of soil (elevated), the degree of saturation with bases is 96.4-97.9 \%, the amount of absorbed bases is 25.5-27.8 mg-eq./ in $100 \mathrm{~g}$ of soil, the content of heavy metals is presented in table 5 .

During the years of study, the meteorological conditions varied in temperature and soil moisture, which made it possible to comprehensively study the effect of the factors used.

\section{Results and discussion}

The yield is the main indicator that characterizes the effectiveness of the use of various agricultural practices in the cultivation of crops. The use of plant growth regulators has a positive effect on obtaining stable high yields [5-7].

The studies have shown that the factors used in the experiment contribute to an increase in yields by $0.17-0.40 \mathrm{t} / \mathrm{ha}$, the application of the growth regulator Energia provides the greatest increase in relation to the control group $(22.3 \%)$ (Table 1$)$.

* Corresponding author: andreev919@yandex.ru 
Their ability to form high-quality products is very important in grain production, in addition to ensuring the realization of the biological potential of a plant's productive capacity.

Grain quality is a total set of the biological, physicochemical, and technological properties of grain, which determine its suitability and ability to satisfy certain needs in accordance with its purpose.

Table 1. The effect of growth regulators on the yield of spring wheat variety Zemlyachka, t/ha

\begin{tabular}{|c|c|c|c|c|c|c|}
\hline \multicolumn{5}{|c|}{ The years of studies } & \multicolumn{2}{|c|}{ Increase } \\
\hline 2010 & 2011 & 2012 & 2013 & average & $\mathrm{t} / \mathrm{ha}$ & $\%$ \\
\hline \multicolumn{7}{|c|}{ Variant Control } \\
\hline 0.65 & 3.61 & 1.28 & 1.61 & 1.79 & - & 100 \\
\hline \multicolumn{7}{|c|}{ Variant Crezacin } \\
\hline 0.70 & 4.19 & 1.65 & 2.05 & 2.15 & 0.36 & 20.0 \\
\hline \multicolumn{7}{|c|}{ Variant Energia } \\
\hline 0.65 & 4.21 & 1.70 & 2.19 & 2.19 & 0.40 & 22.3 \\
\hline \multicolumn{7}{|c|}{ Variant Albit } \\
\hline 0.70 & 3.64 & 1.51 & 1.99 & 1.96 & 0.17 & 9.5 \\
\hline \multicolumn{7}{|c|}{ Variant Gumi } \\
\hline 0.65 & 3.73 & 1.56 & 1.89 & 1.96 & 0.17 & 9.3 \\
\hline \multicolumn{7}{|c|}{ Variant Zircon } \\
\hline 0.75 & 3.71 & 1.60 & 1.85 & 1.98 & 0.19 & 10.6 \\
\hline \multicolumn{7}{|c|}{ Variant Extrasol } \\
\hline 0.70 & 3.80 & 1.49 & 1.95 & 1.99 & 0.20 & 11.0 \\
\hline \multicolumn{7}{|c|}{ Variant $\mathrm{LSD}_{05}$} \\
\hline 0.05 & 0.48 & 0.27 & 0.13 & - & - & - \\
\hline
\end{tabular}

The quality of wheat grain is a factor of intensifying agricultural production, therefore, the improvement of biochemical indicators of production is of key importance in farming and crop growing [8-11]. One of the most important indicators of grain quality, which largely determines its technological properties is the protein content. Protein is a complex set of highmolecular organic compounds, in the element composition of which there are about $53 \%$ carbon, $17 \%$ nitrogen, $7 \%$ hydrogen. Most of the proteins in the grain are in the endosperm, and in solid form, as a reserve substance, which makes them more resistant to chemical and physical effects. In the studies conducted with the action of growth regulators, the protein content of spring wheat grain increased by $0.13-2.13 \%$ over the years of research, depending on the variant, the largest increase was observed in the variants of Crezacin and Energia (Table 2).

Table 2. The effect of growth regulators on the protein content in grain of the spring wheat variety "Zemlyachka", \%

\begin{tabular}{|c|c|c|c|c|c|}
\hline \multirow{2}{*}{ Variant } & \multicolumn{4}{|c|}{ The years of studies } & \multirow{2}{*}{ average } \\
\cline { 2 - 5 } & 2010 & 2011 & 2012 & 2013 & 11.84 \\
\hline Control & 10.87 & 14.10 & 11.07 & 11.33 & 13.05 \\
\hline Crezacin & 12.20 & 14.87 & 13.03 & 12.10 & 13.32 \\
\hline Energia & 12.13 & 15.40 & 13.20 & 12.53 & 13.43 \\
\hline Albit & 11.00 & 14.47 & 12.43 & 12.40 & 12.58 \\
\hline Gumi & 11.31 & 14.37 & 12.33 & 12.10 & 12.53 \\
\hline Zircon & 12.27 & 14.33 & 12.93 & 12.20 & 12.93 \\
\hline Extrasol & 11.60 & 15.17 & 13.07 & 12.30 & 13.03 \\
\hline LSD 05 & 0.28 & 0.52 & 0.55 & 0.61 & - \\
\hline
\end{tabular}

The main indicator that determines the baking properties of grain is the gluten content, which can range from 7.0 to $50 \%$. It forms the so-called backbone or skeleton of bread, causing the gas-holding capacity of dough. With enough good gluten, the dough becomes porous and easy to bake. The quality of gluten and its output depends not only on the varietal characteristics of the grain, but also on the area of cultivation, climatic conditions, and entomological factor. It was found that this indicator in the grain of spring wheat of the Zemlyachka variety increased in comparison with the control group in the variants Crezacin and Energia by $3.27-3.47 \%$ respectively (Table 3 ).

The role of carbohydrates is very important in grain, the main one is starch. When baking bread, starch forms a colloidal system (jelly), which, together with the gluten complex, contributes to the formation of elastic crumb, that is, it creates the structure of bread.

In the conducted studies, with the action of growth regulators, the starch content increased compared to the control group by 2.01-5.08\%, depending on the variant. The best results were observed with the use of growth regulators Crezacin and Energia.

Table 3. The effect of growth regulators on the quantity and quality of gluten in the grain of the spring wheat variety "Zemlyachka", (average over the years of research)

\begin{tabular}{|c|c|c|c|}
\hline Variant & $\begin{array}{c}\text { Mass } \\
\text { fraction } \\
\text { of gluten, } \%\end{array}$ & $\begin{array}{c}\text { Gluten } \\
\text { deformation } \\
\text { index, c.u. }\end{array}$ & $\begin{array}{c}\text { Gluten } \\
\text { quality } \\
\text { group }\end{array}$ \\
\hline Control & 22.44 & 81.11 & II \\
\hline Crezacin & 25.71 & 76.70 & II \\
\hline Energia & 25.91 & 72.70 & I \\
\hline Albit & 24.44 & 77.70 & II \\
\hline Gumi & 24.71 & 75.70 & I \\
\hline Zircon & 24.51 & 74.70 & I \\
\hline Extrasol & 25.01 & 75.60 & I \\
\hline
\end{tabular}

While assessing the milling properties of produce, the test or volumetric weight of grain is performed. Test weight is a representation of the qualitative determination of the grain weight, its conformity with the standards of grain kernels. Whole, developed grain differs in a higher relative content of endosperm. When milling the grain that belongs to a higher grade, you can get more flour than from the grain of a lower grade, with a higher content of hulls. It was found that the largest volumetric weight of spring wheat grain was in the variants with the use of Crezacin and Energia, compared with the control group, the increase was $12.7-14.7 \mathrm{~g} / \mathrm{l}$ (Table 4).

Table 4. The effect of growth regulators on the volumetric weight of the grain of the spring wheat variety Zemlyachka, g/l

\begin{tabular}{|c|c|c|c|c|c|}
\hline \multirow{2}{*}{ Variant } & \multicolumn{4}{|c|}{ The years of studies } & \multirow{2}{*}{ Average } \\
\cline { 2 - 5 } & 2010 & 2011 & 2012 & 2013 & \\
\hline Control & 700.0 & 748.3 & 716.0 & 734.7 & 724.7 \\
\hline Crezacin & 709.0 & 762.7 & 728.0 & 750.3 & 737.5 \\
\hline Energia & 709.7 & 767.3 & 728.7 & 752.3 & 739.5 \\
\hline Albit & 706.3 & 756.0 & 725.0 & 742.0 & 732.3 \\
\hline Gumi & 710.0 & 755.7 & 724.3 & 742.3 & 733.1 \\
\hline Zircon & 711.0 & 756.3 & 727.0 & 747.7 & 735.5 \\
\hline Extrasol & 707.0 & 758.3 & 724.0 & 744.7 & 733.5 \\
\hline
\end{tabular}


Heavy metals occupy one of the priority areas in terms of their prevalence, biohazard and ability to enter trophic chains in agroecosystems among contaminants. An increasing biological, mechanical and chemical load on the components of agroecosystems lead to the fact that the mechanisms of natural self-regulation turn out to be insufficient. As a result, there is a progressive decrease in soil fertility, significant crop losses, deterioration in produce quality [12]. The negative effects of heavy metals on plants are due to their phytotoxic effect and accumulation in crop produce, which poses a threat to human health [13].

As a result of numerous studies, three protective mechanisms have been identified in plants in the way of the penetration of heavy metals into plants: in the soilroot, root-stalk, and stem-grain areas. The data obtained can be used in the system of measures to obtain high quality products. Getting into the "soil-plant-animalhuman" system, heavy metals are included in the biological circulation and food chains, retaining toxic and mutational properties for a long time. This requires the development of adequate technological methods to minimize the negative effects of toxicant aftereffects [14].

An excess of heavy metals in the soil causes negative changes in the physiologically important functions of plants. High concentrations of heavy metals lead to an imbalance of food components in plants and adversely affect the synthesis and functions of many biologically active compounds: enzymes, vitamins, hormones, etc. [15].

In recent years, the possibility of applying plant growth regulators to increase the resistance of crops to adverse factors has been actively explored. Plant growth regulators stimulate growth and root formation, regulate vital processes in plant cells, help to adapt to adverse environmental conditions and protect against diseases due to increased immunity. The use of plant growth regulators leads to an increase in plant resistance to the damaging effects of herbicides and cations of heavy metals, an increase in the content of antioxidants in them, and the prevention of intake of heavy metals and radioactive elements by plants [16-18]. At present, the problem of stress and adaptation of plant organisms to it is very important. The purpose of research is to study the effect of various plant growth regulators on the productivity and content of heavy metals in spring wheat plants.

According to Sanitary regulations 2.3.2. 1078-01 in plant origin products heavy metal salts are subject to mandatory control. However, the accumulation of the same heavy metals in different plants can be very different. According to the degree of accumulation of heavy metals, they are divided into three groups.

The heavy metals determined in our experiment belonged to the following groups: Group 1-Cd (elements of intense absorption), Group 2- $\mathrm{Zn}, \mathrm{Cu}, \mathrm{Pb}, \mathrm{Hg}$ (medium absorption), Group 3 -Ni (weak absorption). In addition, heavy metals are ranked in 3 classes according to the degree of threat to human health (State Standard 17.4.1.02-83). The heavy metals we studied belong to class $1(\mathrm{Hg}, \mathrm{Pb}, \mathrm{Cd}, \mathrm{Zn})$ and class $2(\mathrm{Ni}, \mathrm{Cu})$.
Table 5. The content of heavy metals in the plowing layer of the experimental plot, $\mathrm{mg} / \mathrm{kg}$

\begin{tabular}{|c|c|c|c|}
\hline \multicolumn{2}{|c|}{ Indicators } & Plowing layer 0-30 cm & MPC \\
\hline \multirow{2}{*}{$\mathrm{Zn}$} & Total form & 31.5 & 100 \\
\cline { 2 - 4 } & Active form & 6.5 & 23 \\
\hline \multirow{2}{*}{$\mathrm{Cu}$} & Total form & 14.0 & 55 \\
\cline { 2 - 4 } & Active form & 3.12 & 3 \\
\hline \multirow{2}{*}{$\mathrm{Pb}$} & Total form & 12.7 & 30 \\
\cline { 2 - 4 } & Active form & 2.64 & 6 \\
\hline \multirow{2}{*}{$\mathrm{Cd}$} & Total form & 0.74 & 3 \\
\cline { 2 - 4 } & Active form & 0.4 & 0.6 \\
\hline \multirow{2}{*}{$\mathrm{Ni}$} & Total form & 23.8 & 85 \\
\cline { 2 - 4 } & Active form & 3.52 & 2.1 \\
\hline \multirow{2}{*}{$\mathrm{Hg}$} & Total form & 0.017 & 0.1 \\
\cline { 2 - 4 } & Active form & - & \\
\hline
\end{tabular}

As a result of the research, it was found that presowing treatment of spring wheat seeds with growth regulators contributed to a decrease in the accumulation of heavy metals in the grain. On average for 2010-2012 the content of heavy metals decreased as compared with the control group: $\mathrm{Hg}-$ by $0.0002-0,0005 \mathrm{mg} / \mathrm{kg}, \mathrm{Ni}-$ by $0.02-0.06 \mathrm{mg} / \mathrm{kg}, \mathrm{Pb}-$ by $0.02-0.06 \mathrm{mg} / \mathrm{kg}, \mathrm{Cd}-$ by $0.001-0.005 \mathrm{mg} / \mathrm{kg}, \mathrm{Cu}-$ by $0.20-0.59 \mathrm{mg} / \mathrm{kg}, \mathrm{Zn}-$ by $0.39-0.37 \mathrm{mg} / \mathrm{kg}$, depending on the variant (Table 6).

Table 6. Effect of growth regulators on the content of heavy metals in the grain of spring wheat of the variety "Zemlyachka", mg/kg

\begin{tabular}{|c|c|c|c|c|c|c|}
\hline \multirow[t]{2}{*}{ Variants } & \multicolumn{6}{|c|}{ Mean values for (2010-2012) } \\
\hline & 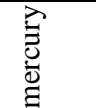 & 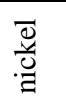 & $\stackrel{\widetilde{E}}{\mathscr{E}}$ & 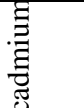 & $\begin{array}{l}\bar{\delta} \\
\stackrel{0}{0} \\
\overline{0}\end{array}$ & . \\
\hline Control & 0.0007 & 0.28 & 0.29 & 0.069 & 7.66 & 28.19 \\
\hline Crezacin & 0.0003 & 0.24 & 0.24 & 0.063 & 7.14 & 27.47 \\
\hline Ener-gia & 0.0002 & 0.22 & 0.23 & 0.062 & 7.07 & 27.49 \\
\hline Albit & 0.0004 & 0.24 & 0.25 & 0.067 & 7.36 & 27.73 \\
\hline Gumi & 0.0005 & 0.25 & 0.27 & 0.068 & 7.38 & 27.70 \\
\hline Zircon & 0.0003 & 0.26 & 0.26 & 0.066 & 7.46 & 27.69 \\
\hline Extra-sol & 0.0003 & 0.23 & 0.25 & 0.065 & 7.40 & 27.80 \\
\hline MPC & 0.03 & 0.50 & 0.50 & 0.10 & 10.0 & 50.0 \\
\hline
\end{tabular}

According to the accumulation level in the grains of spring wheat, the elements to be determined form the following decreasing element series: $\mathrm{Zn}>\mathrm{Cu}>\mathrm{Pb}>\mathrm{Ni}>$ $\mathrm{Cd}>\mathrm{Hg}$. The analysis of the data obtained shows that the most effective treatment of seeds was with the use of Crezacin and Energia.

The content of heavy metals in the produce, regardless of the variant, did not exceed established maximum permissible concentrations. The accumulation intensity of heavy metals by plants can be estimated by the coefficient of biological absorption (CBA), which is the ratio of the element content in the plant ash to its content in the soil. The value of CBA is integral, it characterizes the selective ability of a plant and reflects the proportion of absorbed elements. Calculations in view of the CBA of heavy metals in the produce of experimental crop showed that this indicator is less than one in all variants (Table 7).

The lowest indicators for this coefficient are observed in the variants with Crezacin and Energia. In addition to reducing the accumulation of heavy metals in 
the grains, the growth regulators used in the experiment contribute to an increase in the yield of spring wheat (Table 8).

Table 7. The coefficient of biological absorption in view of the accumulation of heavy metals in the grains of spring wheat of the variety "Zemlyachka"

\begin{tabular}{|c|c|c|c|c|c|c|}
\hline \multirow{2}{*}{ Variants } & \multicolumn{7}{|c|}{ CBA } \\
\cline { 2 - 7 } & $\mathrm{Ni}$ & $\mathrm{Pb}$ & $\mathrm{Cd}$ & $\mathrm{Cu}$ & $\mathrm{Zn}$ & $\mathrm{Hg}$ \\
\hline Control & 0.011 & 0.022 & 0.093 & 0.55 & 0.89 & 0.04 \\
\hline Crezacin & 0.010 & 0.018 & 0.085 & 0.51 & 0.87 & 0.02 \\
\hline Energia & 0.009 & 0.018 & 0.083 & 0.50 & 0.87 & 0.01 \\
\hline Albit & 0.010 & 0.019 & 0.090 & 0.52 & 0.88 & 0.02 \\
\hline Gumi & 0.010 & 0.021 & 0.091 & 0.53 & 0.88 & 0.03 \\
\hline Zircon & 0.011 & 0.020 & 0.089 & 0.53 & 0.88 & 0.02 \\
\hline Extrasol & 0.009 & 0.019 & 0.087 & 0.53 & 0.88 & 0.02 \\
\hline
\end{tabular}

Table 8. Effect of growth regulators on the yield of spring wheat of the variety Zemlyachka, t/ha

\begin{tabular}{|c|c|c|c|c|c|}
\hline Variant & 2010 & 2011 & 2012 & Average & Increase \\
\hline Control & 0.65 & 3.61 & 1.28 & 1.85 & - \\
\hline Crezacin & 1.70 & 4.19 & 1.65 & 2.18 & 0.33 \\
\hline Energia & 0.65 & 4.21 & 1.70 & 2.19 & 0.34 \\
\hline Albit & 0.70 & 3.64 & 1.51 & 1.95 & 0.10 \\
\hline Gumi & 0.65 & 3.73 & 1.56 & 1.98 & 0.13 \\
\hline Zircon & 0.75 & 3.71 & 1.60 & 2.02 & 0.17 \\
\hline Extrasol & 0.70 & 3.80 & 1.49 & 2.00 & 0.15 \\
\hline LSD $_{0,5}$ & 0.05 & 0.48 & 0.2 & - & - \\
\hline
\end{tabular}

On average, over the years of research, an increase in the yield of spring wheat amounted to $0.10-0.34 \mathrm{t} / \mathrm{ha}$, depending on the variant. The best result was observed in the treatment variant with preparations of Crezacin and Energia.

\section{Conclusion}

Thus, growth regulators used for pre-sowing treatment of spring wheat seeds have a positive effect on the yield of the experimental crop and on the grain quality indicators. This is primarily due to the stimulation of metabolic and physiological processes in plants, which is manifested in the intensification of the growth functions of spring wheat, which ultimately contributes to the formation of complex indicators, such as yield and quality. The application of factors used allowed us to obtain a crop with a lower content of heavy metal ions in the final product. The excess of the established level of maximum permissible concentration for the studied heavy metals has not been established. High efficiency of the use of growth regulators is achieved with the obligatory observance of full agricultural technology.

\section{References}

1. V.A. Isaichev, V.G. Polovinkin, E.V. Provalov, The influence of growth regulators and fertilizers on the production processes and yield of winter wheat in the forest-steppe of the Volga region Bull. of the Kurgan State Agricult. Acad. 3, 30-33 (2012)
2. V.A. Isaichev, N.N. Andreev, F.A. Mudarisov, Feeding and technological value of wheat grain and pea seeds Bull. of the Ulyanovsk State Agricult. Acad. 2(18), 24-28 (2012)

3. O.A. Tkachuk, E.V. Pavlikova, A.N. Orlov, The effectiveness of growth regulators in the cultivation of spring wheat in the forest-steppe zone of the Middle Volga Young scientist 4, 677-679 (2013)

4. A.S. Butuzov, The effectiveness of the use of growth regulators in the cultivation of winter wheat Agrar. Bull. of the Urals 11(65), 51-52 (2009)

5. I.I. Galichenko, New varieties - a reserve for increasing grain production Agricult. 3, 45 (2005)

6. I.V. Bakulova, Z.A. Kirsanov, The regulation of the production process of sowing winter triticale and rye with agrotechnical methods Achievements of sci. and technol. of agricult. 5, 17-19 (2009)

7. E.N. Zyuzina, The stimulating effect of bacterial preparations and growth regulators on the formation of the vegetative sphere of spring wheat plants as a factor of increasing yields Proc. of PSPU 5(9), 33-35 (2007)

8. P.P. Vasyukov, G.V. Chuvarleev, V.I. Tsygankov, The influence of predecessors and mineral fertilizers on the yield and grain quality of winter wheat Farming 1, 26-27 (2006)

9. E.N. Shabolkina, A.P. Chichkin, Grain quality of new varieties of spring wheat in the steppe Trans Volga region Achievement of sci. and technol. of the agrar. and industrial complex 11, 14-16 (2009)

10. V.V. Koshelyaev, N.Y. Babaeva, Yield properties of soft wheat seeds depending on the mineral nutrition of mother plants Farming 5, 42-43 (2008)

11. M.I. Dulov, A.P. Trots, Yield and quality of spring soft wheat grain in the forest-steppe zone of the Middle Volga region in the application of resourcesaving cultivation technologies Agricult. Biology 5, 100-104 (2007)

12. L.N. Ulianenko, S.V. Kruglov, A.S. Filipas, N.N. Noah, N.S. Stepanchikova, The effect of soil contamination with cadmium on its accumulation of barley plants in ontogenesis Agrochem. 5, 70-74 (2010)

13. V.S. Barsukova, Physiological and genetic aspects of plant resistance to heavy metals 63 (State public sci. and techn. library of the Siberian branch of the Russ. Acad. of Sci., Novosibirsk, 1997)

14. V.D. Barannikov, N.K. Kirilov, Ecological safety of agricultural produce (Kolos, Moscow, 2008)

15. N.M. Belous, V.V. Talyzin, V.F. Shapovalov, N.K. Simonenko, The effect of fertilizers on the content of nitrogenous substances and heavy metals in potato tubers Agrochem. 3, 22-28 (2010)

16. O.I. Yakhin, A.A. Lubyanov, B.N. Postrigan, A.V. Hemeris, V.A. Vakhitov, R.A. Batraev, The influence of the plant growth regulator Stifun on cadmium accumulation by seedlings of cereal crops Agrochem. 5, 76-83 (2011) 
17. I.I. Seryogina, E.V. Chursina, The effect of Zircon on the spring wheat productivity and the content of heavy metals in produce when soil is contaminated with $\mathrm{Zn}, \mathrm{Cd}$, Pb Agrochem. 9, 66-71 (2010)
18. L.N. Ulianenko, S.P. Arysheva, A.S. Filipas, S.V. Kruglov, N.N. Malevannaya, E.P. Pimenov, The effect of zircon on the growth of wheat and the accumulation of $C d$ in yield Agricult. Biology 1, 3943 (2005) 